\title{
Competition and coexistence of phytoplankton under fluctuating light: experiments with two cyanobacteria
}

\author{
Elena Litchman ${ }^{1,2, *}$ \\ ${ }^{1}$ University of Minnesota, 1987 Upper Buford Circle, St. Paul, Minnesota 55108, USA \\ ${ }^{2}$ Present address: School of Biology, 310 Ferst Drive, Georgia Institute of Technology, Atlanta, Georgia 30332, USA
}

\begin{abstract}
The effects of light fluctuations on phytoplankton competition were examined in the experiments with 2 freshwater cyanobacteria, Anabaena flos-aquae and Phormidium luridum. Light regimes had the same average irradiance of $50 \mu \mathrm{mol}$ photons $\mathrm{m}^{-2} \mathrm{~s}^{-1}$ and included constant light, highlow light fluctuations of 8 and $24 \mathrm{~h}$ periods and light:dark fluctuations of a $24 \mathrm{~h}$ period. A mechanistic model of light competition was used to predict competitive outcomes under these light regimes. The parameter values were obtained experimentally for constant light conditions. In the experiments, A. flos-aquae was rapidly excluded under constant light but persisted under fluctuating light. The model predicted well the dynamics and the outcome of competition under constant light but performed poorly under fluctuating light. The results indicate that light fluctuations may change the dynamics and outcome of competition and slow competitive exclusion and also that competition under fluctuating light cannot necessarily be predicted from the constant light monoculture dynamics.
\end{abstract}

KEY WORDS: Cyanobacteria $\cdot$ Competition $\cdot$ Irradiance $\cdot$ Fluctuations

\section{INTRODUCTION}

Environmental variability plays an important role in ecological communities. Nonequilibrium environmental conditions were set forth to explain the paradox of the plankton, where many species of phytoplankton coexist in a relatively homogeneous environment (Hutchinson 1961, Richerson et al. 1970). One of the important aspects of nonequilibrium environmental conditions is fluctuation in resource levels. Theoretical investigations show that variable resource supply can promote coexistence and increase diversity (Levins 1979, Armstrong \& McGehee 1980, Hsu 1980), thus supporting Hutchinson's explanation of 'the paradox of the plankton' (1961). Experimental studies with phytoplankton showed that fluctuations in major limiting nutrients can alter competitive interactions and increase diversity (Turpin \& Harrison 1979, Sommer 1985, Suttle et al. 1987, Grover 1988, 1990).

Light is a major essential resource in aquatic systems and is highly variable in both time and space. How- ever, surprisingly little attention has been paid to the effects of fluctuating light supply on phytoplankton competition. Brzezinski \& Nelson (1988) considered competition between 2 diatoms for ammonia under fluctuating light of non-limiting levels. They found that a fluctuating light regime facilitated coexistence of both species, while constant light conditions led to competitive exclusion of one of the species. Similarly, van Gemerden (1974) demonstrated that 2 strains of sulfur bacteria were able to coexist under variable light conditions while competing for a substrate. However, no studies have looked at the effects of fluctuating light at limiting levels on competitive interactions among phytoplankton.

Here, I examine how fluctuating light at limiting levels affects competitive interactions in freshwater phytoplankton. Light-limited conditions are not uncommon in natural waters and may result from either a deep mixed layer, high background turbidity (e.g. dissolved organic carbon [DOC] or suspended particles) and/or high biomass of phytoplankton. In eutrophic 
lakes, dense cyanobacterial blooms often create lightlimited conditions where algae compete for light by mutual shading (Klemer 1985, Reynolds 1987). Competition for light among phytoplankton under constant irradiance has been investigated in the experiments of Mur et al. (1977) and Huisman et al. (1999). They showed that a species capable of reducing incident light to the lowest level ( $I_{\text {out, }}$ the incident light level at the bottom of the water column; sensu Huisman \& Weissing 1994) wins competition. At the same time, in natural waters, even in severely light-limited environments, more than 1 species can be found simultaneously, e.g. cyanobacterial blooms can consist of 2 or 3 species (e.g. Anabaena sp., Aphanizomenon sp. and Microcystis sp.) even if a single species dominates (Brock 1985). Could it be possible that fluctuations in light promote coexistence of several species under light-limited conditions as was demonstrated theoretically for limiting resources in general (e.g. Levins 1979, Armstrong \& McGehee 1980) and confirmed experimentally for nutrient-limited phytoplankton (Turpin \& Harrison 1979, Sommer 1984)? I investigate this hypothesis in experiments with 2 cyanobacteria. The 2 species frequently occurring in eutrophic lakes were grown together in constant and fluctuating light under light-limited conditions and their dynamics were monitored. Following Huisman \& Weissing (1994), competitive abilities of each species were determined by growing them in monoculture and estimating $I_{\text {out }}$ at equilibrium. A model of light competition was used to predict competitive outcomes under each light regime.

\section{MATERIALS AND METHODS}

Experimental setup. To investigate the effect of temporal variation in light supply on competition for light between phytoplankton, pairwise competition experiments were performed. Two species of freshwater cyanobacteria, Anabaena flos-aquae (Lyng.) Brébisson (American Type Culture Collection Clone 22664) (hereafter Anabaena) and Phormidium luridum var. olivace Boresch (University of Texas Culture Collection Clone 426) (hereafter Phormidium), were grown under 4 different light regimes. Anabaena often forms extensive blooms and the genus Phormidium is similar to the genus Oscillatoria in its ecological niche and can be either planktonic or benthic (Whitford \& Schumacher 1984). The average incoming irradiance was the same in all treatments, i.e. $50 \mu \mathrm{mol}$ photons $\mathrm{m}^{-2} \mathrm{~s}^{-1}$; however, temporal patterns of light supply differed, i.e. there were the constant light treatment, square-wave fluctuations between 15 and $85 \mu \mathrm{mol}$ photons $\mathrm{m}^{-2} \mathrm{~s}^{-1}$ with 8 or $24 \mathrm{~h}$ periods, and light:dark fluctuations between 0 and $100 \mu \mathrm{mol}$ photons $\mathrm{m}^{-2} \mathrm{~s}^{-1}$ with a $24 \mathrm{~h}$ period. In all 3 fluctuating regimes, periods of low and high irradiance were of equal duration. Algae were grown in $1 \mathrm{l}$ Erlenmeyer flasks (380 ml culture volume) at $20^{\circ} \mathrm{C}$ and gently shaken several times a day. Each treatment had 3 replicates. Treatments were assigned randomly to environmental chambers. Flask positions were determined so that the irradiance levels at the surface of the flasks were within 1 to $2 \mu \mathrm{mol}$ photons $\mathrm{m}^{-2} \mathrm{~s}^{-1}$ of the required levels as measured with a quantum scalar sensor (Biospherical Instruments QSL-100). Light was provided by 'cool white' fluorescent tubes (Philips); flasks were illuminated from all sides except the bottom. Fluctuations in irradiance were imposed by periodically turning on and off additional light sources.

Full strength WC freshwater medium (Guillard 1975) with $2 \times$ standard concentration of $\mathrm{NaHCO}_{3}$ was used to achieve high filament densities and light-limited conditions for both species as well as competition for light by mutual shading. A higher concentration of inorganic carbon was used to increase the buffering capacity of the medium and the availability of inorganic carbon (both species are known to successfully utilize $\mathrm{HCO}_{3}{ }^{-}$as a source of inorganic carbon; Allen \& Spence 1981, Novak \& Brune 1985, E. Litchman \& J. Shapiro unpubl.) and have very high affinity for $\mathrm{CO}_{2}$ (Shapiro 1997). The cultures were buffered with bicarbonate rather than synthetic buffers to avoid possible effects of buffer salts on growth by altering cell membrane permeability (Novak \& Brune 1985). In nature, cyanobacterial blooms are often associated with mildly alkaline bicarbonate-rich waters (Klemer 1985, Reynolds 1987). $\mathrm{NaHCO}_{3}$ was added aseptically after autoclaving to prevent precipitation.

Cultures were started at relatively low densities of each species (ca. $10^{3}$ filaments $\mathrm{ml}^{-1}$ ) and were grown for $6 \mathrm{~d}$ in batch regime. After reaching higher densities, cultures were switched to a semicontinuous regime: once per day, $65 \mathrm{ml}$ of a culture was replaced by fresh sterilized WC medium with a doubled $\mathrm{HCO}_{3}{ }^{-}$ concentration (dilution rate of $0.19 \mathrm{~d}^{-1}$ ). Such a relatively low dilution rate was chosen to ensure that slow growing Anabaena (Fig. 1) would not be washed out. Growth-irradiance curves for each species were determined in separate experiments under constant irradiance (Litchman 2000) (Fig. 1). The minimum irradiance at which growth is non-negative under this dilution rate is 3 and $12 \mu \mathrm{mol}$ photons $\mathrm{m}^{-2} \mathrm{~s}^{-1}$ for Phormidium and Anabaena, respectively, as determined from their growth-irradiance curves (Fig. 1). These values agreed well with the results of a pilot experiment where a monoculture of Phormidium was able to grow at $I_{\text {in }}$ (incoming irradiance) $=5 \mu \mathrm{mol}$ photons $\mathrm{m}^{-2} \mathrm{~s}^{-1}$, while a monoculture of Anabaena could not persist at this irradiance and a given dilution rate. 


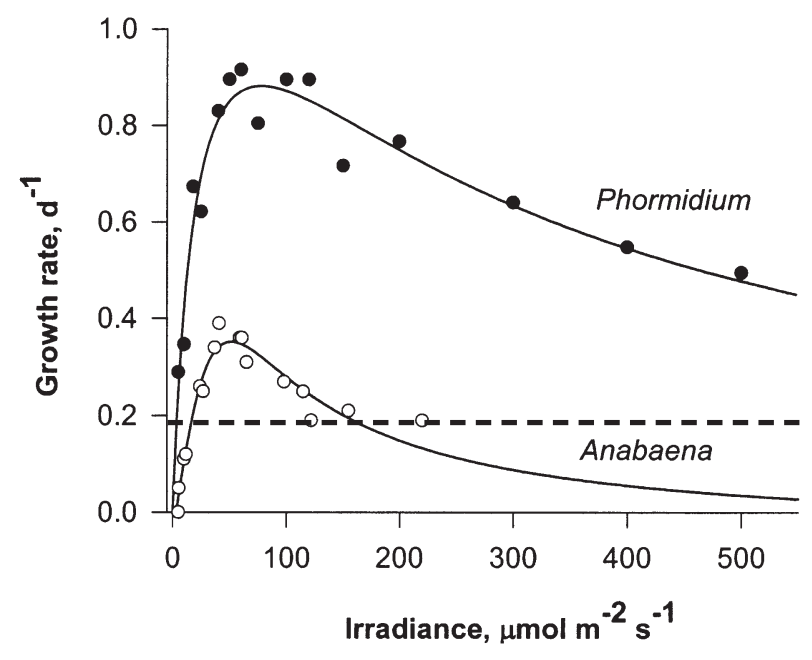

Fig. 1. Phormidium and Anabaena. Growth-irradiance curves of Phormidium and Anabaena determined in separate experiments under constant irradiance (Litchman 2000). Dilution (mortality) rate is shown with a dashed line. Parameter values of Eq. (2) are the following: $g_{\max , A n a}=1.19 \mathrm{~d}^{-1}, g_{\max , \text { Phorm }}=$ $1.4 \mathrm{~d}^{-1}, \mathrm{k}_{\text {Ana }}=42 \mu \mathrm{mol}$ photons $\mathrm{m}^{-2} \mathrm{~s}^{-1}, \mathrm{k}_{\text {Phorm }}=22 \mu \mathrm{mol}$ photons $\mathrm{m}^{-2} \mathrm{~s}^{-1}, \mathrm{k}_{\mathrm{inh}, \text { Ana }}=61 \mu \mathrm{mol}$ photons $\mathrm{m}^{-2} \mathrm{~s}^{-1}, \mathrm{k}_{\mathrm{inh}, \text { Phorm }}=$ $267 \mu \mathrm{mol}$ photons $\mathrm{m}^{-2} \mathrm{~s}^{-1}$

After species densities reached stationary phase, phosphorus $\left(\mathrm{PO}_{4}-\mathrm{P}\right)$ and nitrogen $\left(\mathrm{NO}_{3}-\mathrm{N}\right.$ and $\left.\mathrm{NH}_{4}-\mathrm{N}\right)$ concentrations were measured according to Strickland \& Parsons (1972) to check for nutrient-replete conditions. pH was measured periodically (in the middle of the low and high light periods in the fluctuating light regimes) to assess carbon availability. The experiment was run for $12 \mathrm{wk}$, samples were taken once or twice per week, preserved with Lugol's iodine and counted in a $1 \mathrm{ml}$ Sedgwick-Rafter chamber. To determine species density, at least 500 filaments were counted for each sample, and if a species was rare in a sample, the whole chamber was scanned. Filament and cell sizes were measured with an ocular-micrometer and compared among treatments throughout the course of experiment. The average number of cells per filament for each treatment was determined by counting cells in 20 random filaments for each species in each treatment during the course of experiment.

To characterize the minimum light requirements of the species, each was grown in monoculture under constant light regime, and the incident light levels were estimated at equilibrium. According to resource competition theory, a species that is able to attenuate light to the lowest point (e.g. measured at the bottom of the water column, $I_{\text {out }}$ ), should win competition (Tilman 1982, Huisman \& Weissing 1994). In contrast to nutrient competition where the minimum resource level $\left(R^{*}\right)$ is independent of supply rate, the $I_{\text {out }}$ depends on the incoming irradiance (Huisman \&
Weissing 1994). Therefore, it is necessary to determine $I_{\text {out }}$ values under the same irradiance as was used in the pairwise experiment. I used the $I_{\text {out }}$ as an estimate of species competitive abilities. This measure, although proposed by Huisman \& Weissing (1994) for unidirectional light field, appears to be robust even when the assumption of unidirectionality is relaxed (Weissing \& Huisman 1994). Light levels were measured directly outside the flask with a cosine quantum sensor connected to a Li-Cor data logger. Species-specific attenuation coefficients, $a_{\mathrm{i}}$ were determined by estimating light attenuation in monocultures after they reached stationary phase:

$$
a=\ln \left(I_{\mathrm{in}} / I_{z}\right) / z
$$

where $I_{\text {in }}$ is the incoming light, and $I_{\mathrm{z}}$ is light at depth $z$ (thickness of the culture volume), measured immediately outside the flask. The attenuation coefficient was then normalized by the filament density. The background attenuation was determined the same way, measuring the light attenuation in the growth medium without algae.

To determine whether monocultures reached equilibrium due to limitation by light, rather than another resource, a series of nutrient additions (nitrate, phosphate, bicarbonate and concentrated WC solution) were performed and the densities of species were monitored. Biomass responses were estimated by measuring optical densities of cultures at $750 \mathrm{~nm}\left(\mathrm{OD}_{750}\right)$. At the end of experiment, cell densities in each monoculture were compared to the densities of monocultures grown under the same experimental conditions, but at higher irradiance: $75 \mu \mathrm{mol}$ photons $\mathrm{m}^{-2} \mathrm{~s}^{-1}$. Higher species densities at higher irradiances would indicate light-limited conditions.

Model. To describe light competition of the 2 species, I used a model based on the model proposed by Huisman \& Weissing (1994):

$$
\begin{aligned}
& \frac{\mathrm{d} b_{i}}{\mathrm{~d} t}=\frac{1}{Z} \int_{0}^{z} g_{\mathrm{i}}[I(s)] b_{i} \mathrm{~d} s-D b_{i} \\
& i=2 \\
& I(s)=I_{\text {in }} \exp \left[-\left(\sum_{i=1}^{\mathrm{n}} a_{i} b_{i} s+a_{\mathrm{bg}} s\right)\right]
\end{aligned}
$$

where $b_{i}$ is the filament density of the $i$ th species (filaments $\left.\mathrm{ml}^{-1}\right), t$ is time, $z$ is the depth of the culture $(\mathrm{cm})$, $g_{\mathrm{i}}$ is the irradiance-dependent growth function, $D$ is mortality $\left(\mathrm{d}^{-1}\right), I(s)$ is the irradiance at depth $s, I_{\text {in }}$ is the incoming irradiance, $a_{\mathrm{i}}$ is the attenuation coefficient for species $i\left(\mathrm{~cm}^{2}\right.$ filament $\left.{ }^{-1}\right)$ and $a_{\mathrm{bg}}$ is the background attenuation $\left(\mathrm{cm}^{-1}\right)$. Attenuation coefficients were determined as desribed above. For the species used in the experiments, the growth is described by the following function with photoinhibition: 


$$
g_{i}=g_{\text {max }, i} \frac{I}{I+\mathrm{k}_{i}+\frac{I^{2}}{\mathrm{k}_{\mathrm{inh}, i}}}
$$

where $g_{\text {max }, i}$ is the maximum growth rate $\left(\mathrm{d}^{-1}\right), I$ is the incident irradiance ( $\mu \mathrm{mol}$ photons $\mathrm{m}^{-2} \mathrm{~s}^{-1}$ ), $\mathrm{k}_{i}$ is the constant and $k_{i n h, i}$ is the photoinhibition constant (Megard et al. 1984). Growth parameters for both species were determined in separate experiments under constant irradiance (Litchman 2000) (Fig. 1).

\section{RESULTS AND DISCUSSION}

The temporal regime of light supply had a significant effect on the population dynamics of species and on competitive trends in the community. Phormidium was dominant under all 4 light regimes. Anabaena was excluded in the constant light treatment but was able to persist under fluctuating light regimes throughout the experiment (Fig. 2). Both species were able to grow

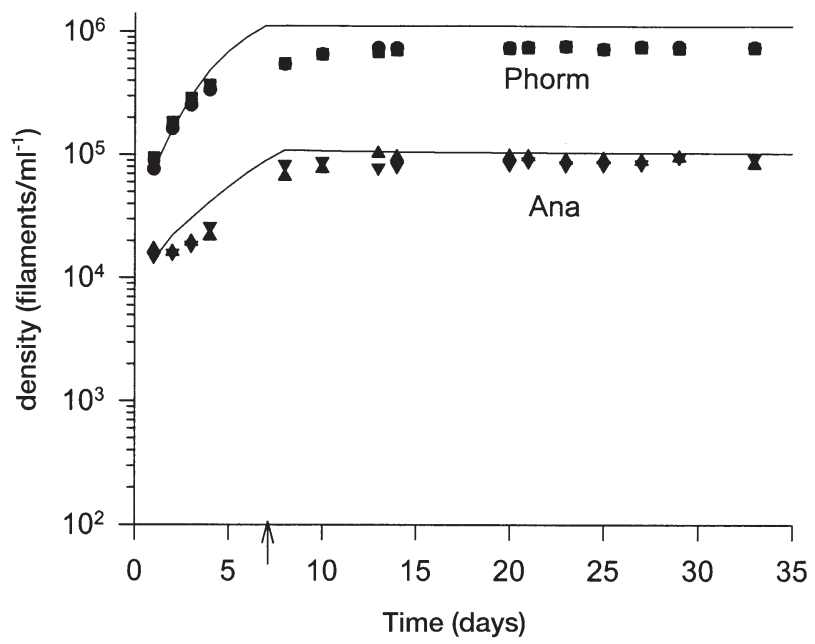

Fig. 3. Anabaena and Phormidium. Observed growth dynamics (symbols) of Anabaena and Phormidium in monoculture under constant light. The arrow shows when cultures were switched from batch to semicontinuous regime. The dynamics predicted by the model are also shown (lines)
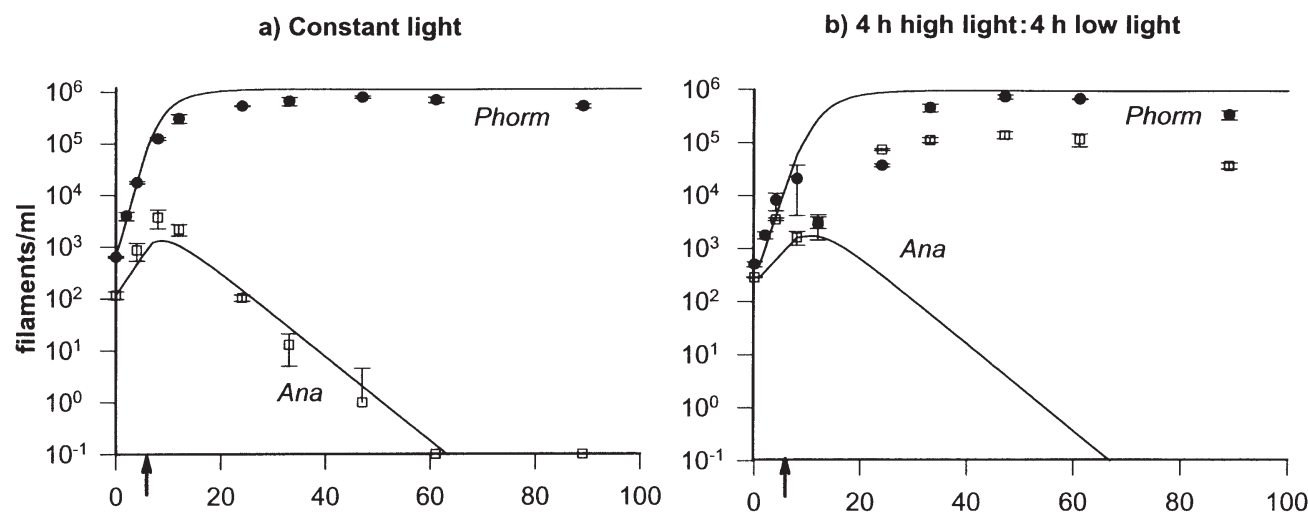

c) $12 \mathrm{~h}$ high light: $12 \mathrm{~h}$ low light

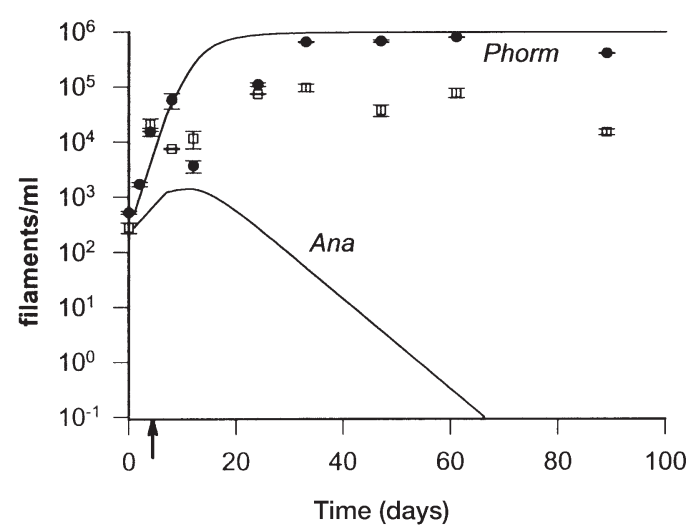

d) $12 \mathrm{~h}$ high light: $12 \mathrm{~h}$ dark

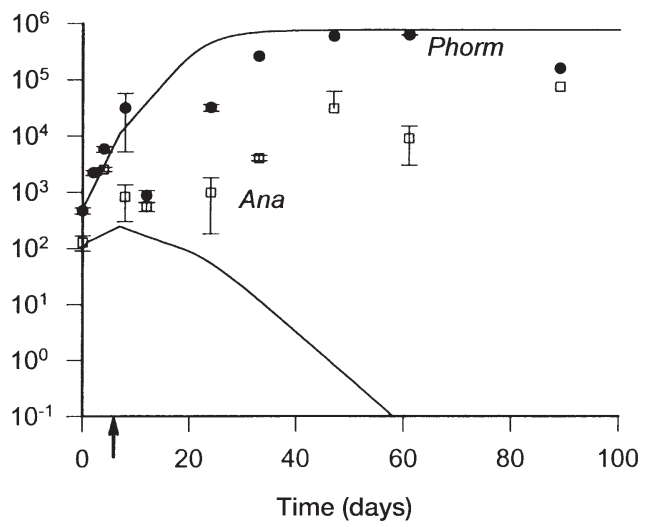

Fig. 2. Phormidium (•) and Anabaena (). Species dynamics in the course of the pairwise experiment under 4 different light regimes. Means \pm SEM are shown. (a) Constant light, (b) fluctuating light, $8 \mathrm{~h}$ period, (c) fluctuating light, $24 \mathrm{~h}$ period, (d) light:dark fluctuations, $24 \mathrm{~h}$ period. The vertical arrow on the abscissa marks the time of the first dilution. Lines are model predictions. Species parameters are as in Fig. 1 and $\mathrm{D}_{\text {Ana }}=0.2 \mathrm{~d}^{-1}, \mathrm{D}_{\text {Phorm }}=0.19 \mathrm{~d}^{-1}, \mathrm{k}_{\text {Ana }}=5.2 \times 10^{-6} \mathrm{~cm}^{2}$ filament ${ }^{-1}, \mathrm{k}_{\text {Phorm }}=$ $1.7 \times 10^{-6} \mathrm{~cm}^{2}$ filament $^{-1}, \mathrm{k}_{\mathrm{bg}}=0.066 \mathrm{~cm}^{-1}$ 
in monoculture under these experimental conditions (Fig. 3), which suggests that Anabaena's exclusion resulted from competitive interactions between the 2 species. $I_{\text {out }}$ during Anabaena's decline $(24 \mathrm{~d}$ from the start of the experiment) was between $1 \mu \mathrm{mol}$ photons $\mathrm{m}^{-2} \mathrm{~s}^{-1}$ (as estimated from the absorbance spectra of the cultures where $\overline{\mathrm{OD}}=0.56$ ) and $7 \mu \mathrm{mol}$ photons $\mathrm{m}^{-2} \mathrm{~s}^{-1}$ (attenuation due to absorption only). Thus, the incoming light was reduced by more than 85 to $98 \%$ by the species biomass. At the end of the experiment, the light attenuation was even higher $\left(\overline{\mathrm{OD}}=0.67,0.5<I_{\text {out }}\right.$ $<6 \mu \mathrm{mol}$ photons $\mathrm{m}^{-2} \mathrm{~s}^{-1}$ ). The light attenuation in the light:dark treatments after $24 \mathrm{~d}$ from the start of experiment was lower than in the constant or fluctuating light treatments due to lower biomass of both species (as estimated from the OD measurements). There was a significant drop in species density in the fluctating light treatments after dilutions began and no such drop in the constant light treatment. Later in the course of experiment, the estimated light levels were not significantly different among treatments.

The average light at the bottom of the suspension $\left(I_{\text {out }}\right)$ in the monoculture of Phormidium was significantly lower than that in the monoculture of Anabaena (0.8 to $1 \mu \mathrm{mol}$ photons $\mathrm{m}^{-2} \mathrm{~s}^{-1}$ for Phormidium vs $5 \mu \mathrm{mol}$ photons $\mathrm{m}^{-2} \mathrm{~s}^{-1}$ for Anabaena), indicating that under these experimental conditions Phormidium is a better competitor for light and should displace Anabaena, as was observed in the experiment.

Nitrogen and phosphorus concentrations were above limiting levels $(10 \mu \mathrm{M}$ phosphorus and $70 \mu \mathrm{M}$ nitrogen; Horne \& Goldman 1994); also, the occurrence of heterocysts in Anabaena in treatments was similar to that in dilute nutrient-replete cultures (an increase in heterocyst frequency could indicate nitrogen deficiency). Additions of nutrients did not affect the equilibrium densities of either species (as inferred from the $\mathrm{OD}_{750}$ measurements), which suggests that nutrients did not limit growth. The average $\mathrm{pH}$ values in the pairwise experiment were $9.1 \pm 0.3$ under constant light and ranged from 8.2 during the low light period to 9.7 during the high light period under fluctuating light. For light:dark fluctuations, the range was even wider: from ca. 7.6 in the dark to 9.8 during the light period. The $\mathrm{pH}$ values in monocultures after they reached equilibrium were comparable to the $\mathrm{pH}$ values in the pairwise experiment and did not exceed 9.4 for either species (under constant light), although both species are able to grow at $\mathrm{pH} \geq 10$ in water with similar concentrations of inorganic carbon (0.2 mM; Shapiro 1997). The addition of bicarbonate to the monocultures after they reached stationary phase did not change their densities (measured as $\mathrm{OD}_{750}$ ), which indicates adequate carbon availability during the experiment, since both species can utilize bicarbonate (e.g. Allen \& Spence 1981).

At higher incident light $\left(75 \mu \mathrm{mol}\right.$ photons $\left.\mathrm{m}^{-2} \mathrm{~s}^{-1}\right)$, the densities of each species were higher than at $50 \mu \mathrm{mol}$ photons $\mathrm{m}^{-2} \mathrm{~s}^{-1}\left(9.9 \times 10^{5}\right.$ filaments $\mathrm{ml}^{-1}$ for Phormidium and $1.2 \times 10^{5}$ filaments $\mathrm{ml}^{-1}$ for Anabaena), indicating the presence of light limitation under the experimental conditions.

To examine trends in competitive dynamics, linear regression was fitted to the time series of the natural logarithms of the ratio of population density of Anabaena to that of Phormidium (Grover 1988). The data from the first $12 \mathrm{~d}$ of the experiment were not included in the analysis to minimize transient effects associated with the change to semicontinuous regime. The rate of competitive exclusion for each light regime was estimated as a slope of the fitted regression line (Grover 1988). The rate was greatest under constant light; high:low light fluctuations of the 2 fluctuation periods had much lower, but still significantly non-0 rates. There was no significant difference in the rates of the 2 high-low light fluctuation regimes. In contrast, under the light:dark fluctuations, the slope of the regression line was not significantly different from 0 (Table 1), which suggests the possibility for stable coexistence under this light regime. To test whether stable coexistence was achieved in this case the invasion scenario experiments (Tilman \& Sterner 1984) should be performed.

The average filament size of Phormidium was not significantly different among treatments throughout the experiment (average dimensions were $2 \times 46 \mu \mathrm{m}$ ). The average filament length of Anabaena, however, was sensitive to the regime of light supply and, after about 2 wk from the start, was significantly shorter under constant light compared to the 3 fluctuating light regimes for all dates until Anabaena's disappear-

Table 1. Linear regression of $\ln$ (Anabaena density/Phormidium density) versus time for different light regimes. The rate of competitive exclusion of Anabaena by Phormidium is determined as a slope of the regression line

\begin{tabular}{|c|c|c|c|c|c|}
\hline Light regime & & Estimate & $\mathrm{SE}$ & $t$-value & p-value \\
\hline Constant light & $\begin{array}{l}\text { Intercept } \\
\text { Slope }\end{array}$ & $\begin{array}{l}-5.39 \\
-0.14\end{array}$ & $\begin{array}{l}1.68 \\
0.03\end{array}$ & $\begin{array}{l}-3.2 \\
-4.2\end{array}$ & $\begin{array}{l}0.03 \\
0.01\end{array}$ \\
\hline $\begin{array}{l}\text { Fluctuating light, } \\
t=8 \mathrm{~h}\end{array}$ & $\begin{array}{l}\text { Intercept } \\
\text { Slope }\end{array}$ & $\begin{array}{r}0.49 \\
-0.05\end{array}$ & $\begin{array}{l}0.59 \\
0.01\end{array}$ & $\begin{array}{r}0.84 \\
-3.02\end{array}$ & $\begin{array}{l}0.44 \\
0.04\end{array}$ \\
\hline $\begin{array}{l}\text { Fluctuating light, } \\
t=24 \mathrm{~h}\end{array}$ & $\begin{array}{l}\text { Intercept } \\
\text { Slope }\end{array}$ & $\begin{array}{r}0.69 \\
-0.05\end{array}$ & $\begin{array}{l}0.78 \\
0.015\end{array}$ & $\begin{array}{r}0.88 \\
-3.36\end{array}$ & $\begin{array}{l}0.43 \\
0.03\end{array}$ \\
\hline $\begin{array}{l}\text { Light:dark } \\
\text { fluctuations, } t=24 \mathrm{~h}\end{array}$ & $\begin{array}{l}\text { Intercept } \\
\text { Slope }\end{array}$ & $\begin{array}{l}-2.9 \\
0.005\end{array}$ & $\begin{array}{l}1.53 \\
0.03\end{array}$ & $\begin{array}{r}-1.89 \\
0.17\end{array}$ & $\begin{array}{l}0.13 \\
0.87\end{array}$ \\
\hline
\end{tabular}




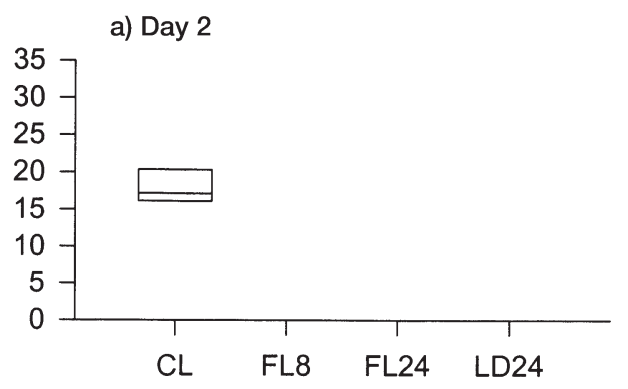

b) Day 25
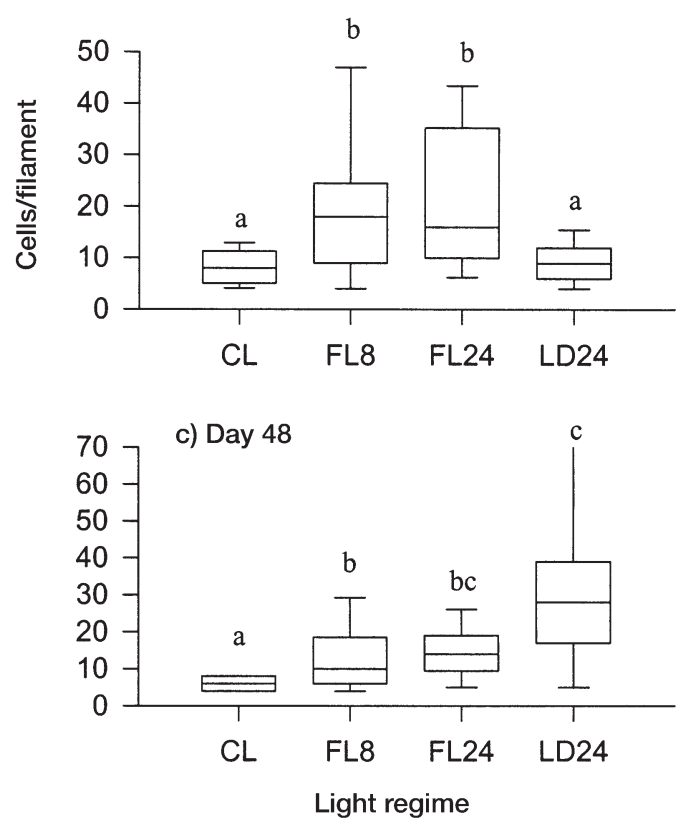

Fig. 4. Anabaena. Average number of cells per filament of Anabaena in the pairwise experiment under different light regimes. CL, constant light treatment; FL8 and FL24, highlow light fluctuations with 8 and $24 \mathrm{~h}$ periods, respectively; LD24, light:dark fluctuations of $24 \mathrm{~h}$ period. Kruskal-Wallis test was used for treatment comparisons. Treatments with no common letters are significantly different $(p<0.05)$

ance from the constant light treatment (Fig. 4). Shorter filament length in cyanobacteria is often associated with lower growth rates and physiological stress (Meffert 1971).

The specific attenuation coefficients were $5.2 \times$ $10^{-6} \mathrm{~cm}^{2}$ filament ${ }^{-1}$ for Anabaena and $1.7 \times 10^{-6} \mathrm{~cm}^{2}$ filament ${ }^{-1}$ for Phormidium, which is comparable to the reported value for another filamentous cyanobacterium Aphanizomenon flos-aquae (Huisman et al. 1999). The higher specific attenuation coefficient of Anabaena could in part be explained by the higher concentration of chlorophyll a $(\mathrm{chl} a)$ in its filaments: under the given irradiance, chl a concentrations were $2.05 \pm 0.07 \mathrm{pg}$ filament $^{-1}$ for Phormidium and $3.66 \pm$ $0.05 \mathrm{pg}$ filament $^{-1}$ for Anabaena (as measured in a separate experiment; unpubl.).
Comparison of experimental dynamics with model predictions

In general, the predicted dynamics of species in monocultures agreed with the observed dynamics (Fig. 3). The model predicted slightly higher densities of Phormidium than were observed. There was also a noticeable lag phase in Anabaena's growth in the experiment, which was not predicted by the model (Fig. 3).

The model predicted competitive exclusion of Anabaena by Phormidium under constant light regime. Overall, the predicted dynamics of both species in mixed cultures agreed well with the observed dynamics, although, similar to monoculture predictions, the model predicted higher densities of Phormidium than were observed in the experiment (Fig. 2). The model predicted competitive exclusion of Anabaena under fluctuating light, occurring at a rate similar to that under the constant light, while in the experiment under fluctuating light, no competitive exclusion was observed for the duration of the experiment (Fig. 2). Thus, the model was not able to adequately predict competitive interactions under fluctuating light regimes.

There are several possible reasons for the inadequate prediction of the competition dynamics under fluctuating light. First, dynamic responses of algae to fluctuations not included in the models might have altered the dynamics of competition under fluctuating light. As growth experiments show (Litchman 2000), under the fluctuating light regimes used in this study, growth rates of Anabaena in monoculture increased, compared to the constant light regime, possibly due to a delayed onset of photoinhibition and/or a non-0 growth in the dark, while the growth rates of Phormidium did not. Such enhancement of growth by fluctuations that may have enabled Anabaena to persist under fluctuating light could not be predicted from Anabaena's steady-state growth-irradiance curve on which the model was based. Other studies have shown that growth rates change in response to light fluctuations (Nicklisch \& Fietz 2001). It is conceivable that the inability of the steady-state model to describe species responses to fluctuations could also lead to poor prediction of competition under fluctuating light. A model that includes the dynamic responses of species to fluctuations and, thus, better describes growth in monoculture may be needed to model competition under fluctuating light. Alternatively, growth-irradiance curves would have to be obtained for each fluctuation regime. If the persistence of both species under fluctuating light is due to species-specific growth rate changes, then coexistence may not have occurred if both species would respond to fluctuations in a similar way.

Another possible reason for increased persistence of Anabaena under fluctuating light regimes is that fluc- 
tuations might have altered the minimum light requirements of species compared to constant light, so that Anabaena was able to grow at lower light levels. A decrease in the minimum light requirements under $24 \mathrm{~h}$ light:dark cycles compared to constant light was documented previously for some species (Reynolds 1987).

The persistence of Anabaena under fluctuating light regimes could have also been due to buoyancy changes of the Anabaena filaments. Low light levels ( 5 to $35 \mu \mathrm{mol}$ photons $\mathrm{m}^{-2} \mathrm{~s}^{-1}$ ) were shown to increase buoyancy of Anabaena (Reynolds 1997), possibly due to lower carbohydrate content (Gibson 1978). Brookes et al. (1999) found that light fluctuations maintained higher buoyancy of Anabaena circinalis compared to the continuous high light conditions. If fluctuating light regimes caused increase in buoyancy, Anabaena could have greater access to light (since no constant mixing was imposed), thus increasing its competitive ability. Theoretical studies showed that a spatial segregation of species along the light gradient may promote coexistence of several species (e.g. Britton \& Timm 1993, Klausmeier \& Litchman 2001). To focus on non-spatial mechanisms of persistence, well-mixed cultures need to be used.

It is also possible that, despite light limitation, the exclusion of Anabaena by Phormidium occurred due to competition for other resource, possibly carbon. Although monocultures did not respond to additions of bicarbonate, the decreased availability of free $\mathrm{CO}_{2}$ with increased $\mathrm{pH}$ may have contributed to Anabaena's decline. Even though the average $\mathrm{pH}$ values in the constant and fluctuating light treatments were not significantly different, the temporal variation in $\mathrm{pH}$ and, consequently, in the availability of inorganic carbon could have been important. As the modeling investigation (Litchman \& Klausmeier 2001) and the experiments by Brzezinski \& Nelson (1988) suggest, light fluctuations, by mediating competition for a nutrient, may lead to a reversal of competitive outcome reached under constant light or increased perisistence of both competitors. Additional experiments are needed to test these hypotheses and to identify the exact mechanism for Anabaena's increased persistence under fluctuating light.

The results of this study demonstrate that fluctuations in light supply may significantly affect competitive interactions of species and promote coexistence. Light fluctuations can increase diversity in multispecies communities as well (Litchman 1998, Flöder et al. 2002). Low light levels and relatively high $\mathrm{pH}$ values are common in productive lakes, often dominated by cyanobacteria. As results of this study suggest, fluctuations in light supply, including daily light:dark cycles, may lead to a long-term (several months) persistence of more than 1 species of cyanobacteria, depending on their responses to light fluctuations. This time is comparable to time-scales of successional sequence in temperate lakes. Thus, temporal heterogeneity in light supply may contribute to phytoplankton diversity in nature.

Acknowledgements. This research was in part supported by the National Science Foundation Doctoral Dissertation Improvement grant, Sigma Xi Society grant and the Summer Fellowship from the Ecology Department of the University of Minnesota. Assistance of A. Phillips and comments by J. Grover, C. Klausmeier, A. Klemer, R. Sterner and the anonymous reviewers are greatly appreciated.

\section{LITERATURE CITED}

Allen ED, Spence HN (1981) The differential ability of aquatic plants to utilize the inorganic carbon supply in fresh waters. New Phytol 87:269-283

Armstrong RA, McGehee R (1980) Competitive exclusion. Am Nat 115:151-169

Britton NF, Timm U (1993) Effects of competition and shading in planktonic communities. J Math Biol 31:655-673

Brock TD (1985) A eutrophic lake: Lake Mendota, Wisconsin. Springer-Verlag, New York

Brookes JD, Ganf GG, Green D, Whittington J (1999) The influence of light and nutrients on buoyancy, filament aggregation and floatation of Anabaena circinalis. J Plankton Res 21:327-341

Brzezinski MA, Nelson DM (1988) Interactions between pulsed nutrient supplies and a photocycle affect phytoplankton competition for limiting nutrients in long-term culture. J Phycol 24:346-356

Flöder S, Urabe J, Kawabata Z (2002) The influence of fluctuating light intensities on species composition and diversity of natural phytoplankton communities. Oecologia 133: 395-401

Gibson CE (1978) Carbohydrate content as an ecological tool in the study of planktonic blue-green algae. Verh Int Ver Theor Angew Limnol 20:630-635

Grover JP (1988) Dynamics of competition in a variable environment: experiments with 2 diatom species. Ecology 69: 408-417

Grover JP (1990) Resource competition in a variable environment: phytoplankton growing according to monod's model. Am Nat 136:771-789

Guillard RRL (1975) Culture of phytoplankton for feeding marine invertebrates. In: Smith WL, Chanley MH (eds) Culture of marine invertebrate animals. Plenum Press, New York, p 29-60

Horne AJ, Goldman CR (1994) Limnology. McGraw-Hill, New York

Hsu SB (1980) A competition model for a seasonally fluctuating nutrient. J Math Biol 9:115-132

Huisman J, Weissing FJ (1994) Light-limited growth and competition for light in well-mixed aquatic environments: an elementary model. Ecology 75:507-520

Huisman J, Jonker RR, Zonneveld C, Weissing FJ (1999) Competition for light between phytoplankton species: experimental tests of mechanistic theory. Ecology 80:211-222

Hutchinson GE (1961) The paradox of the plankton. Am Nat 95:137-145

Klausmeier CA, Litchman E (2001) Algal games: the vertical 
distribution of phytoplankton in poorly mixed water columns. Limnol Oceanogr 46:1998-2007

Klemer AR (1985) Nutrient-induced migrations of blue-green algae (Cyanobacteria). Mar Sci 27:153-165

Levins R (1979) Coexistence in a variable environment. Am Nat 114:765-783

Litchman E (1998) Population and community responses of phytoplankton to fluctuating light. Oecologia 117:247-257

Litchman E (2000) Growth rates of phytoplankton under fluctuating light. Freshw Biol 44:223-235

Litchman E, Klausmeier CA (2001) Competition of phytoplankton under fluctuating light. Am Nat 157:170-187

Meffert ME (1971) Cultivation and growth of 2 planktonic Oscillatoria species. Mitt Int Ver Limnol 19:189-205

Megard RO, Tonkyn DW, Senft WH (1984) Kinetics of oxygenic photosynthesis in planktonic algae. J Plankton Res 6:325-337

Mur LR, Gons HJ, Liere LV (1977) Some experiments on the competition between green algae and blue-green cyanobacteria in light-limited environments. FEMS Microbiol Ecol 1:335-338

Nicklisch A, Fietz S (2001) The influence of light fluctuations on growth and photosynthesis of Stephanodiscus neoastrea (diatom) and Planktothrix agardhii (cyanobacterium). Arch Hydrobiol 151:141-156

Novak JT, Brune DE (1985) Inorganic carbon limited growth kinetics of some freshwater algae. Water Res 19:215-225

Reynolds CS (1987) Cyanobacterial water blooms. Adv Bot Res 13:67-143

Richerson PJ, Armstrong R, Goldman CR (1970) Contemporaneous disequilibrium, a new hypothesis to explain the para-

Editorial responsibility: William Li,

Dartmouth, Nova Scotia, Canada dox of the plankton. Proc Natl Acad Sci USA 67:1710-1714 Shapiro J (1997) The role of carbon dioxide in the initiation and maintenance of blue-green dominance in lakes. Freshw Biol 37:307-323

Sommer U (1984) The paradox of the plankton: fluctuations of phosphorus availability maintain diversity of phytoplankton in flow-through cultures. Limnol Oceanogr 29:633-636

Sommer U (1985) Comparison between steady state and nonsteady state competition: experiments with natural phytoplankton. Limnol Oceanogr 30:335-346

Strickland JD, Parsons T (1972) A practical manual of seawater analysis. Bull Fish Res Board Can 167

Suttle CA, Stockner JG, Harrison PJ (1987) Effects of nutrient pulses on community structure and cell size of a freshwater phytoplankton assemblage in culture. Can J Fish Aquat Sci 44:1768-1774

Tilman D (1982) Resource competition and community structure. Princeton University Press, Princeton, NJ

Tilman D, Sterner RW (1984) Invasions of equilibria: tests of resource competition using 2 species of algae. Oecologia (Berlin) 61:197-200

Turpin DH, Harrison PJ (1979) Limiting nutrient patchiness and its role in phytoplankton ecology. J Exp Mar Biol Ecol 39:151-166

van Gemerden H (1974) Coexistence of organisms competing for the same substrate: an example among the purple sulfur bacteria. Microb Ecol 1:104-119

Weissing FJ, Huisman J (1994) Growth and competition in light gradient. J Theor Biol 168:323-326

Whitford LA, Schumacher GJ (1984) A manual of fresh-water algae. Sparks Press, Raleigh, NC

Submitted: August 29, 2002; Accepted: December 23, 2002 Proofs received from author(s): March 6, 2003 